\title{
Educational Technology Research Trends: A Bibliometrics Analysis And Visualization
}

\author{
Nerru Pranuta Murnaka, \\ Department of Mathematics Education, STKIP Surya. Tangerang. Indonesia, \\ nerru.pranuta@stkipsurya.ac.id, ORCID : https://orcid.org/0000-0002-2698-1586. \\ Suwarno, \\ Department of Primary Teacher Education, Faculty of Humanities, Bina Nusantara University. \\ Jakarta. Indonesia, suwarno2@binus.edu, ORCID : https://orcid.org/0000-0002-8989-6100. \\ Rusdarti, \\ Universitas Negeri Semarang, Indonesia, rusdarti@mail.unnes.ac.id. \\ Rustono, \\ Universitas Negeri Semarang, Indonesia.rustono@mail.unnes.ac.id. \\ I Made Sudana, \\ Universitas Negeri Semarang, Indonesia.sudana@mail.unnes.ac.id. \\ Tri Joko Raharjo, \\ Universitas Negeri Semarang, Indonesia, trijokoraharjo@mail.unnes.ac.id.
}

\begin{abstract}
Educational Technology has been developing in recent years. The implementation of educational technology has collaborated in several fields such as social scienc-es, computer science, engineering, and medicine. In this study, the researcher has conducted a bibliometric analysis of educational technology research during the period 1971 to 2019 . A total of 8,134 bibliographic data have collected from the Scopus database. VOSviewer software are used for analysis. In the bibliometric analysis, various extracted metadata include journals and affiliations, citations, keyword distribution, many cited papers, and the most influential authors and journals. This study shows the development status and trends in educational technology. On the other hand, this study can be used as a reference for research and application of bibliometric analysis
\end{abstract}

Keywords: bibliometrics analysis, educational technology, scopus.

\section{INTRODUCTION}

The development of information and communication technology massively corre-lates to the increase in digital data. We live in a world where vast amounts of data are collected every day. Analyzing the data is an essential requirement. One of the digital data is publication data. Data can be collected and explored using a technique called data mining. Data mining is the process of finding interesting patterns and knowledge from a large amount of data. Data sources can include databases, data warehouses, the Web, other information repositories, or data that is streamed to the system dy-namically (Han, J., Kamber, M., \& Pei, J. ,2012). In this study, researchers conducted educational technology research data mining.

At present, the role of educational technology in teaching is very important be-cause of the use of information and communication technology [Stošić, L. (2015).). Education digi-talization has an expanded meaning, with the help of digital solutions and infor-mation systems, student access to the best university education resources in the world, to remote data from the results of scientific experiments and research, to the library of tasks and technical problems, and the creation of a workforce team, distributed research and education [3]. Educational technology is a systematic and or-ganized process in applying modern technology to improve the quality of education (efficiency, optimal, correct, etc.). This is a systematic way to conceptualize the implementation and evaluation of the educational process, i. e. learning and teaching, and assisting in the application of modern educational teaching techniques [2]. Learning outside the classroom is also possible because of technology. Students are no longer limited to face-to-face learning because technological advances have al-lowed students to choose whether they want to attend classes either face-to-face or through online or both [4].

The main contribution of this study is a bibliometric analysis using one of the most widely used databases, Scopus. Bibliometrics is the cross-disciplinary science of quantitative analysis of all knowledge carriers by mathematical and statistical meth-ods [5]. The researcher selects significant parameters such as the most 
productive writer, the most influential writer, the most quoted discipline, state, and affiliation. We have shown the top 10 in each parameter. The most common keywords from this field are visualized using VOSviewer. This paper is organized as follows: Section 2 explains the data collection process and the methods used in this paper. The results of a detailed bibliometric analysis are carried out in Section 3. The final section con-cludes the paper by summarizing the results.

This research has the main objective of analyzing quantitative and visual to comb the existing literature and get accurate results for the development of educa-tional technology research and future research trends. This study has approved quan-titative research based on bibliometric analysis and knowledge mapping with the support of Scopus, Publish or Perish, and VOSviewer databases.

\section{METHODS}

In this study, we have collected bibliometric data from one of the most commonly used repositories, Scopus. Scopus (http://www.scopus.com/home.url) is an abstract and citation database of peer-reviewed literature and also part of SciVerse provided by Elsevier as described in the section before and therefore based at the same database as ScienceDirect [6]. The results from this database have been summarized according to information regarding the development of the publication. The keywords that have been used for searching in the Scopus database are TITLE-ABS-KEY ("educational technology") AND (LIMIT-TO (EXACTKEYWORD, "Educational Technology") OR LIMIT-TO (EXACTKEYWORD, "Educational Technologies ")) AND (LIMITTO (DOCTYPE," ar ") OR LIMIT-TO (DOCTYPE," cp ")) and a search was carried out in April 2020. From Scopus, we took several tags such as author, title, abstract, country, citation notes, author affiliations etc. and obtained 8,134 documents. From the documents extracted in Scopus classified into Article $(4,133)$ and conference paper $(4,001)$.

In this paper, various performance indicators have been extracted for bibliometric analysis. Total Papers for the total number of publications from the source, Total citations to find out the total number of citations received by the publication, and citation per paper to find out the total number of citations received divided by the total publications. The bibliometric method, which is used in this research, takes advantage of modern technology in computer engineering, database management, and statistics. The bibliometric method can assess future development trends or research orientations using the author's keywords, title keywords, and plus keywords [7]. Until now, bibliometrics has been widely used in the analysis of co-authorship, co-citation analysis, and development of all fields [8]. The bibliometric approach, together with VOSviewer software, is used to quantitatively evaluate global scientific research on educational technology from 1971 to 2019.

\section{RESULTS}

Bibliometric or Scientometric Analysis is a field of research that helps analyze the latest trends in the literature about a particular area and provides guidance and motivation for future research work [9]. The scientific field is the study of science, technology, and innovation from a quantitative perspective. The scientometric perspective adds a quantitative focus on text and communication to interdisciplinary science and technology [10]. In this section, we have shown bibliometric results for various performance parameters including documents by year, documents by author, documents by affiliation, documents by country, documents by source title, documents by subject area, most productive and highly cited authors, most sought after disciplines, and top journals.

\subsection{Most Productive Country}

A total of 8,134 articles were published by authors from 124 countries/regions. Figure 1 shows the total number of publications in Scopus. In Scopus, publication began in 1971 with a total of 1 document and increased exponentially. The highest number of publications is 2019 with 963 documents. The number of documents by country is shown in Figure 2. Figure 2 shows a map of the top 10 countries that con-tributed research on gamification. Based on figure 2, the United States is the top con-tributor with 2,248 documents (27.64\%). The rapid growth of educational technology in the United States shows a clear impact on improving the quality of education in America. China and Australia contributed the second and third with 703 documents (8.64\%) and 569 documents $(7 \%)$ respectively. At present, technological develop-ments in China are increasing. The development of technology in China reached the field of Education. In China, educational technology is an 
important part of content for teacher professional development. Almost all universities in China offer technology courses for prospective teachers and school teachers for further study [11]. United Kingdom and Spain each contribute with a number of important publications from the total literature.

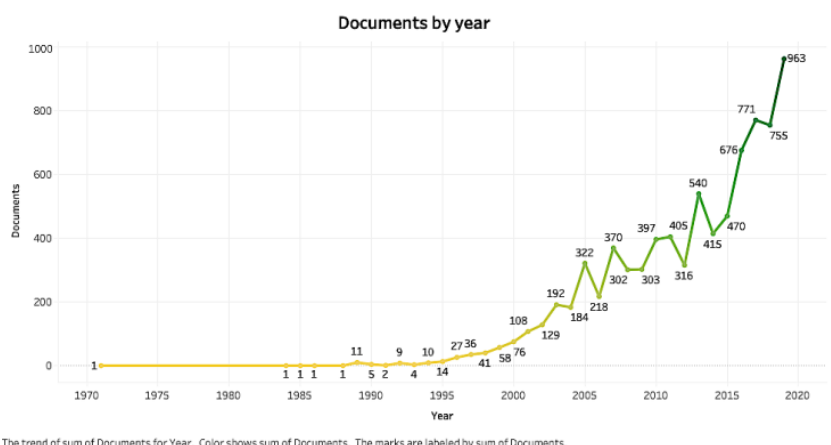

FIGURE 1. Total number of publications in Scopus

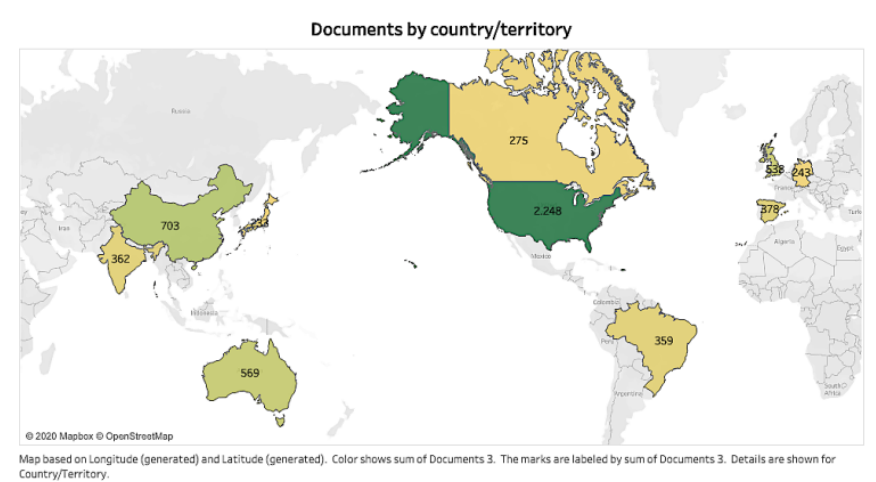

FIGURE 2. Top 10 most productive country

\subsection{Most Productive Affiliation And Subject Area}

Figure 3 shows the top 10 most productive based on affiliation. Based on the data it can be concluded that the five most significant contributors in educational technology research are Huazhong Normal University 114 documents (1.40\%), University of Sao Paulo 63 documents (0.77\%), University of Melbourne 55 documents $(0.67 \%)$, Monash University 45 documents $(0.55 \%)$, and The Open University of Hong Kong 43 documents $(0.52 \%)$. On the other hand, documents based on the subject area are shown in Figure 4 . Based on the data obtained by the five most significant contributors in the subject area namely Social Sciences 4.172 documents (51.29\%), Computer Science 3.954 documents (48.61\%), Engineering 1,511 documents (18.57\%), Medicine 1,335 documents (16.41\%), and Mathematics 529 documents $(6.50 \%)$.

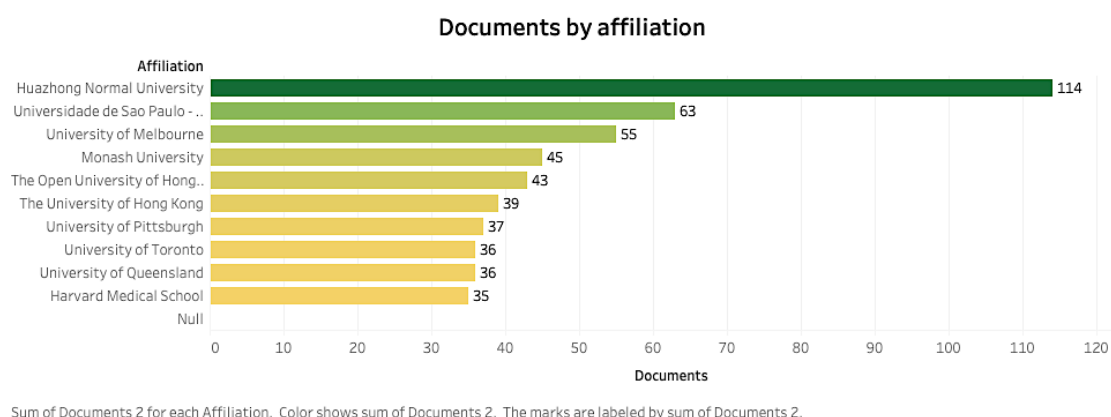

FIGURE 3. Top 10 most productive affiliation 


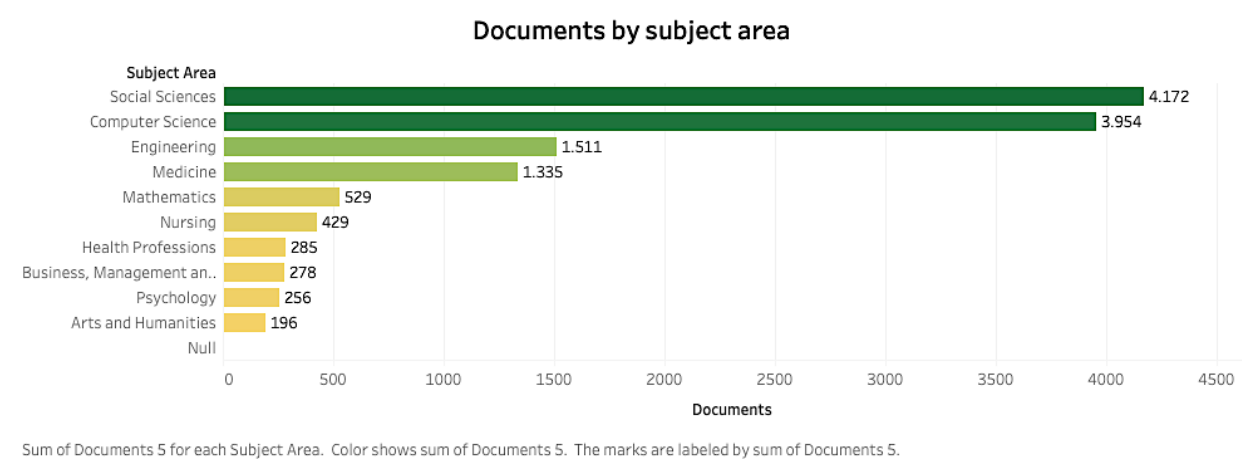

FIGURE 4. Top 10 subject areas covered by educational technology

\subsection{Most Productive And Highly Cited Authors}

The number of citations is a significant factor to reflect the quality of publications [12]. The most productive authors in Scopus are sorted by number of publications. We analyzed the data using Publish or Perish software. Publish or Perish can do a quick literature review to identify the most cited articles in a particular field. This can be used to identify whether research has been conducted in a particular area or to evaluate the development of literature on a particular topic from time to time [13]. From Table 1, the five most productive writers are Liu, H. (1.37\%), Zhang, Z. (0.47\%), Ellaway, R. (0.38\%), Yang, H.H. (0.30\%), and Shu, J. (0.22\%). On the other hand, Liu, H. and Ellaway, R. are the most cited writers. Skiba, D.J., Ng, K.K., and Shu, J. are positioned in 3rd, 4th and 5th place on the list.

Table 1. Top 10 most productive and higly cited authors

\begin{tabular}{lcccc}
\hline \multicolumn{1}{c}{ Author Name } & Paper & Citations & $\begin{array}{c}\text { Cites/ } \\
\text { year }\end{array}$ & $\begin{array}{c}\text { Cites/ } \\
\text { paper }\end{array}$ \\
\hline Liu, H. & 112 & 1,403 & 73.84 & 12.53 \\
Zhang, Z. & 39 & 99 & 6.19 & 2.54 \\
Ellaway, R. & 31 & 517 & 34.47 & 16.68 \\
Yang, H.H. & 25 & 71 & 6.45 & 2.84 \\
Shu, J. & 18 & 151 & 7.95 & 8.39 \\
Skiba, D.J. & 16 & 269 & 16.81 & 16.81 \\
Lai, I.K.W. & 16 & 19 & 4.75 & 1.19 \\
Ng, K.K. & 15 & 40 & 8.00 & 2.67 \\
Peres, H.H.C. & 13 & 68 & 5.23 & 5.23 \\
Kaneda, S. & 11 & 18 & 1.20 & 1.64 \\
\hline
\end{tabular}

\subsection{Top Source/Journal}

In this section, we have extracted the top ten most productive sources or journals in the field of educational technology. The top sources or journals most frequently cited in the field of educational technology were analyzed using Publish or Perish software. A summary of the ten most frequently published analyzes or journals are shown in Table 2. ACM International Conference Proceeding Series (3.23\%), Ceur Workshop Proceedings (2.36\%), Communications in Computer and Information Science (2.23\%), Lecture Notes in Computer Science (1.97\%), and British Journal of Educational Technology (1.76\%).

Table 2. Top 10 journals publishing works on educational technology

\begin{tabular}{lcccc}
\hline \multicolumn{1}{c}{ Source/Journal Name } & Paper & Citations & $\begin{array}{c}\text { Cites/ } \\
\text { year }\end{array}$ & $\begin{array}{c}\text { Cites/ } \\
\text { paper }\end{array}$ \\
\hline $\begin{array}{l}\text { - ACM International Conference } \\
\begin{array}{l}\text { Proceeding Series } \\
\text { - Ceur Workshop Proceedings }\end{array}\end{array}$ & 193 & 401 & 28.64 & 2.01 \\
- Communications in Computer and & 182 & 242 & 17.29 & 1.21 \\
\end{tabular}




\begin{tabular}{lcccc}
\hline \multicolumn{1}{c}{ Source/Journal Name } & Paper & Citations & $\begin{array}{c}\text { Cites/ } \\
\text { year }\end{array}$ & $\begin{array}{c}\text { Cites/ } \\
\text { paper }\end{array}$ \\
\hline $\begin{array}{l}\text { Information Science } \\
\text { - Lecture Notes in Computer Science }\end{array}$ & 161 & 829 & 27.63 & 4.15 \\
- British Journal of Educational & 149 & 6310 & 134.26 & 31.55 \\
$\quad \begin{array}{l}\text { Technology } \\
\text { - Journal of Dental Education }\end{array}$ & 123 & 1957 & 65.23 & 10.81 \\
- Computers and Education & 94 & 11303 & 403.68 & 56.52 \\
- Medical Teacher & 88 & 4697 & 114.56 & 33.31 \\
- IEEE Transaction on Education & 71 & 1635 & 36.33 & 20.19 \\
- Proceedings Frontiers in Education & 62 & 302 & 10.79 & 3.82 \\
$\quad$ Conference Fie & & & & \\
\hline
\end{tabular}

\subsection{Keyword Analysis Of Research Hotspot On Educational Technology}

In this section, we study content by analyzing keyword distribution. Keywords co-occurrence can effectively reflect the research hotspots in the discipline fields, provid-ing auxiliary support for scientific research [14]. The co-occurrence keyword network of educational technology was built by VOSviewer software. VOSviewer software is used to do data mining, mapping, and grouping articles were taken. The size of the circle is positively correlated with the appearance of keywords in the title and ab-stract. Therefore, the size of the item label and circle is determined by the weight of the item. The higher the weight of the item, the greater the label, and circle of the item [15]. The distance between the two nodes reflects the strength of the relationship between the two nodes. Shorter distances generally indicate stronger relationships. The line between the two keywords states that they have appeared together [16]. The link strength between two nodes refers to the frequency of cooccurrence. It can be used as a quantitative index to depict the relationship between two nodes [17]. Figure 5 provides a visualization of the most popular keywords used by writers on Scopus. In all publications related to educational technology, we get 3,344 keywords at a time. The keyword "teaching" has the highest occurrence of 2375. Other keywords with a high occurrence include "education" (2317), "students" (1981), "e-learning" (1550).

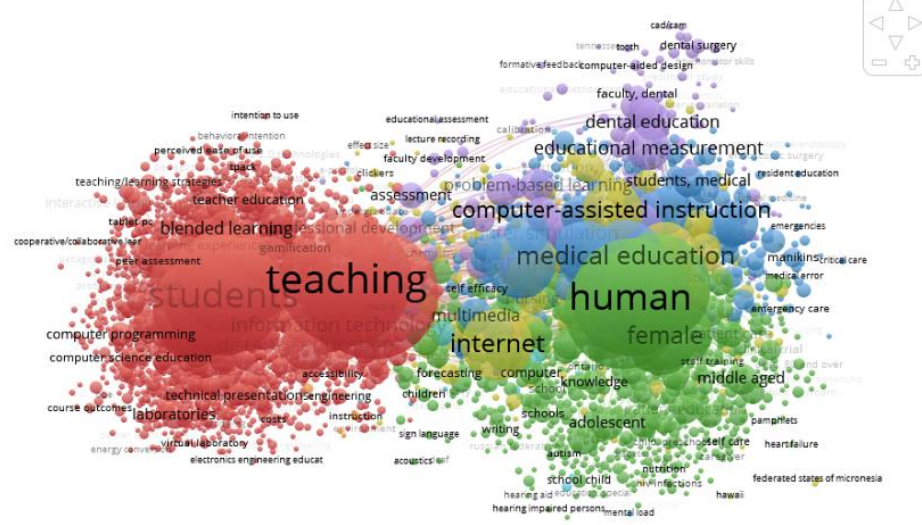

FIGURE 5. The analysis of keyword co-occurrence on educational technology

Table 3. The top 10 keywords of educational technology

\begin{tabular}{clcc}
\hline Rank & \multicolumn{1}{c}{ Keywords } & Occurrences & Total Link Strength \\
\hline 1 & Teaching & 2375 & 35816 \\
2 & Education & 2317 & 35391 \\
3 & Students & 1981 & 21785 \\
4 & Human & 1925 & 41335 \\
5 & E-learning & 1550 & 16768 \\
6 & Engineering education & 1296 & 13653 \\
7 & Learning systems & 843 & 9019 \\
8 & Medical education & 762 & 15908
\end{tabular}




\begin{tabular}{clccc}
\hline Rank & \multicolumn{2}{c}{ Keywords } & Occurrences & Total Link Strength \\
\hline 9 & $\begin{array}{l}\text { Computer } \\
\text { instruction }\end{array}$ & aided & 733 & 8296 \\
10 & Internet & & 711 & 14273 \\
\hline
\end{tabular}

VOSviewer can make density visualizations (see Figure 6). Each node in the keyword density visualization plate has a color that depends on the item density at that node. In other words, the color of a node depends on the number of items in the node environment. Keywords in the red area appear more often; conversely, keywords in green areas appear less frequently (Liao et al., 2018). From Figure 6, we can see the focus of research studies of educational technology intuitively. "Human", "teaching", and "students" are essential keywords. These keywords are the core keywords in the study of educational technology.

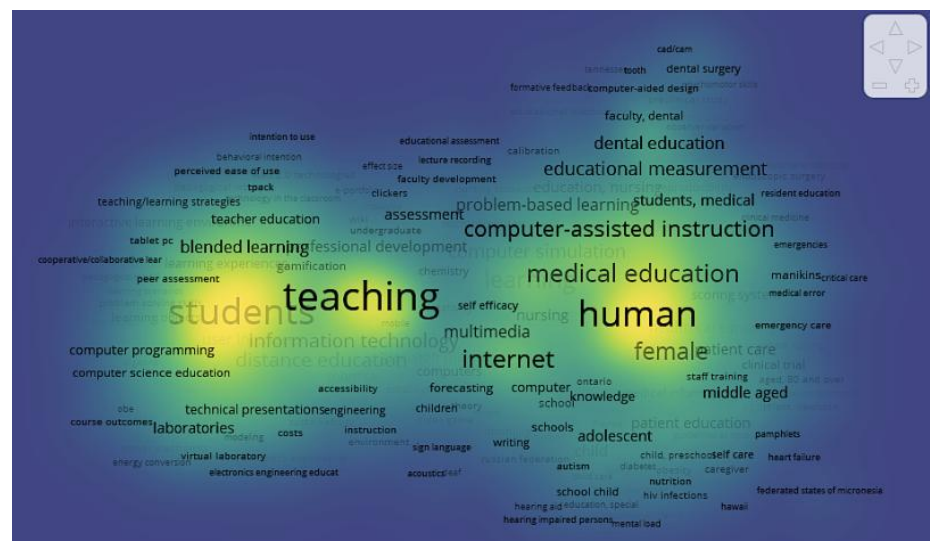

FIGURE 6. Keywords density visualization map of educational technology

\section{CONCLUSIONS}

In this paper, an emerging bibliometric analysis in the field of educational technology has been carried out. The bibliometric analysis helps find structure and development in this field. One widely used repository used for bibliometric analysis is Scopus. Based on the Scopus database, there were 8,134 publications related to educational technology. The United States, China, and Australia are ranked in the top three countries for total educational technology research publications. Besides, three subject areas that are the focus of educational technology studies are Social Science, Computer Science, and Engineering. The three most cited writers are Liu, H., Ellaway, R., and Skiba, D.J. Keyword analysis offers exciting insights into the dynamics of the field of educational technology. In all publications related to educational technology, we get 3,344 keywords at a time. The keyword "teaching" has the highest occurrence of 2375. Other keywords with a high occurrence include "education" (2317), "students" (1981), "e-learning" (1550). "Human", "teaching", and "students" are essential keywords. These keywords are the core keywords in the study of educational technology. A limitation of this study is that the bibliometric study provides several papers and their citations. However, the number of publications only indicates the quantity and does not show quality. Subsequent research, more analysis using other indexing databases such as Web of Science or Google Scholar.

\section{CONFLICT OF INTEREST}

No conflict of interest

\section{REFERENCES}

[1] Han, J., Kamber, M., \& Pei, J. (2012). Data Mining: Concepts and Techniques. Elsevier Inc.

[2] Stošić, L. (2015). The importance of educational technology in teaching. International Journal of Cognitive Research in Science, Engineering and Education, 3(1), 111-114. https://www.scopus.com/inward/record.uri?eid=2-s2.085010378986\&partnerID=40\&md5=17aaaad2283ac63e314ee60a50ffc291 
[3] Shatunova, O., Anisimova, T., Sabirova, F., \& Kalimullina, O. (2019). Steam as an innovative educational technology. Journal of Social Studies Education Research, 10(2), 131-144.

[4] Delgado, A. J., Wardlow, L., McKnight, K., \& O’Malley, K. (2015). Educational technology: A review of the integration, resources, and effectiveness of technology in K-12 classrooms. Journal of Information Technology Education: Research, 14(2015), 397-416. https://doi.org/10.28945/2298

[5] Merigo, J. M., Blanco-Mesa, F., Gil-Lafuente, A. M., \& Yager, R. R. (2016). Thirty Years of the International Journal of Intelligent Systems: A Bibliometric Review. International Journal of Intelligent Systems, 00, 1-34. https://doi.org/10.1002/int

[6] Tober, M. (2011). PubMed, ScienceDirect, Scopus or Google Scholar - Which is the best search engine for an effective literature research in laser medicine? Medical Laser Application, 26(3), 139-144. https://doi.org/10.1016/j.mla.2011.05.006

[7] Chen, D., Liu, Z., Luo, Z., Webber, M., \& Chen, J. (2016). Bibliometric and visualized analysis of emergy research. Ecological Engineering, 90, 285-293. https://doi.org/10.1016/j.ecoleng.2016.01.026

[8] Merigó, J. M., Cancino, C. A., Coronado, F., \& Urbano, D. (2016). Academic research in innovation: a country analysis. Scientometrics, 108(2), 559-593. https://doi.org/10.1007/s11192-016-1984-4

[9] Muhuri, P. K., Shukla, A. K., \& Abraham, A. (2019). Industry 4.0: A bibliometric analysis and detailed overview. Engineering Applications of Artificial Intelligence, 78(November 2018), 218-235. https://doi.org/10.1016/j.engappai.2018.11.007

[10] Leydesdorff, L., \& Milojević, S. (2015). Scientometrics. International Encyclopedia of the Social \& Behavioral Sciences: Second Edition, 21, 322-327. https://doi.org/10.1016/B978-0-08-0970868.85030-8

[11] Meifeng, L., Jinjiao, L., \& Cui, K. (2010). Educational technology in China. British Journal of Educational Technology, 41(4), 541-548. https://doi.org/10.1111/j.1467-8535.2010.01094.x

[12] Tahamtan, I., Safipour Afshar, A., \& Ahamdzadeh, K. (2016). Factors affecting number of citations: a comprehensive review of the literature. Scientometrics, 107(3), 1195-1225. https://doi.org/10.1007/s11192-016-1889-2

[13] Harzing, A.-W. (2011). The publish or perish book: Your guide to effective and responsible citation analysis/Anne-Wil Harzing (1st ed.). Tarma Software Research.

[14] Li, H., An, H., Wang, Y., Huang, J., \& Gao, X. (2016). Evolutionary features of academic articles cokeyword network and keywords co-occurrence network: Based on two-mode affiliation network. Physica A: Statistical Mechanics and Its Applications, 450, 657-669. https://doi.org/10.1016/j.physa.2016.01.017

[15] Xie, L., Chen, Z., Wang, H., Zheng, C., \& Jiang, J. (2020). Bibliometric and Visualized Analysis of Scientific Publications on Atlantoaxial Spine Surgery Based on Web of Science and VOSviewer. World Neurosurgery, February. https://doi.org/10.1016/j.wneu.2020.01.171

[16] Liao, H., Tang, M., Luo, L., Li, C., Chiclana, F., \& Zeng, X. J. (2018). A bibliometric analysis and visualization of medical big data research. Sustainability (Switzerland), 10(1), 1-18. https://doi.org/10.3390/su10010166

[17] Pinto, M., Pulgarín, A., \& Escalona, M. I. (2014). Viewing information literacy concepts: A comparison of two branches of knowledge. Scientometrics, 98(3), 2311-2329. https://doi.org/10.1007/s11192013-1166-6 